\title{
TRANSITION OF STAGE TECHNIQUES FROM SHAKESPEAREAN TO MODERN AGE
}

\author{
Mrs. Neha Sharma \\ Asst. Professor,
} Govt. Maharani LaxmiBai Girls P.G. College, Indore

There are several techniques employed in presenting any art form. Stage is one of the most important element among these technique. It is the medium where one can show the talent and skills in front of audience. A place where selection, designing, adaptation and modification of any performance takes place is called stage. The stages used from ancient to modern age are the symbols of inheriting art and tradition of a generation to another generations. It can also be said that the visual detailing of any play, drama or art form can be technically performed on stage.

The Elizabethan age is specially known for Shakespeare's play. The plays which were used to perform on the stages present in Shakespeare private theaters. There are many technical changes took place simultaneously in the stage craft from Elizabethan to modern age.

The stage of Shakespeare's time were not separated from audience with a curtain that could be used to drop and open during the performance. The end of the scenes can be followed by the exit of the actors from the stage. There were movable sceneries behind the scenes for the change in location. Other than sceneries of forest, palaces, gardens and battlefields, thestageswere also embellished with the properties like tomes, thrones, beds, and rocks etc. which were used according to the demand of the scene.

Shakespeare's plays and dramas were generally based on romance, comedy and tragedy which requires not only stage but also its other levels like trap door which is present under the stage or aerial props like ropes and winches to elevate the actors towards heaven. The stage technique of Elizabethan age is well known for the easy and live views of men to perform in place of women and the big reason behind using men instead of women is that there were no women works on stage at that time.

Behind the stage there was a tiring room and a yard for the actors to change their costumes. Usually,candles and the lanterns were the source of lighting on stage. The sound effects were created manually to express varied situations in the scenes. Sound on the stage was only helpful to reach the audiences ears. There were no advance audio devices used for plays at that time. Actors used to deliver dialogues orally instead of using mic or any audio device.

In the modern days stages are not only used to perform plays but also used to give musical concerts, cultural programs and literally presentation. The main element of modern stage includes the things like position of actors referred to blocking in which their gestures and movements are decided. In addition to this a very advanced and digitized scenic background is 


\section{INTERNATIONAL JOURNAL Of RESEARCH -GRANTHAALAYAH

used to give a glimpsed of original locations. The props and costumes are chosen from the contemporary fashion in order to appeal the audiences.

Besides this lighting and sound effects of modern stage are quite advanced where the specific focus lights are used on specific parts of stage at specific moments. The blocking is used in performance regarding to an actor's position and appearance. It can also be helped to change the significance of the scene. The stage manager is employed to manage the light and sound recording for a better presentation of staging skills. There are several effects implemented on the modern stage to increase the visuals attractions of scenes like rains, snowfalls and fog etc.

The time has accordingly changed the requirements of stage and its technicality. The transitions of old patterned stage into new one is all according to the requirement and demand of audience. Stage is always called a platform to transmit and connect ones skills in front of mass and with working technical equipment's used on stage the skills can be performed excellently. 